CARDIOVASCULAR MEDICINE

\title{
Effects of spironolactone on endothelial function, vascular angiotensin converting enzyme activity, and other prognostic markers in patients with mild heart failure already taking optimal treatment
}

\author{
J E Macdonald, N Kennedy, A D Struthers
}

Heart 2004;90:765-770. doi: 10.1136/hrt.2003.017368

See end of article for authors' affiliations

Correspondence to: Professor Allan D

Struthers, Department of Clinical Pharmacology and Therapeutics, Ninewells Hospital and Medical School, Dundee DD19SY, UK; a.d.struthers@

dundee.ac.uk

Accepted 27 October 2003

\begin{abstract}
Objectives: To examine whether the favourable effects on endothelial function, vascular angiotensin converting enzyme (ACE) activity, cardiac remodelling, autonomic function, and QT intervals of spironolactone in combination with ACE inhibitor also occur in patients with New York Heart Association class I-II congestive heart failure (CHF) taking optimal treatment (including $\beta$ blockers).

Methods: Double blind, crossover study comparing $12.5-50 \mathrm{mg} / 24$ hours spironolactone (three months) with placebo in 43 patients with class I-II CHF taking ACE inhibitors and $\beta$ blockers.

Results: Acetylcholine induced vasodilatation improved with spironolactone $(p=0.044)$. Vascular ACE activity fell $(p=0.006)$. QTc and QTd fell (mean (SD) QTc $473(43.1) \mathrm{ms}$ with placebo, $455(35.4) \mathrm{ms}$ with spironolactone, $p=0.002$; QTd 84.5 (41.3) ms with placebo, 72.1 (32.3) ms with spironolactone, $\mathrm{p}=0.037)$. $\beta$-Type natriuretic peptide (BNP) and procollagen III $\mathrm{N}$-terminal peptide (PIIINP) concentrations were also reduced by spironolactone (mean (SD) BNP $48.5(29.6) \mathrm{pg} / \mathrm{ml}$ with placebo, $36.8(28.5) \mathrm{pg} / \mathrm{ml}$ with spironolactone, $\mathrm{p}=0.039 ;$ PIIINP $3.767(1.157) \mu \mathrm{g} / \mathrm{ml}$ with placebo, 3.156 $(1.123) \mu \mathrm{g} / \mathrm{ml}$ with spironolactone, $p=0.000$ ).

Conclusions: Spironolactone improves vascular function (endothelial function, vascular ACE activity) and other markers of prognosis (BNP, collagen markers, and QT interval length) in asymptomatic or mild CHF when added to optimal treatment including $\beta$ blockade. This gives support to the hypothesis that the prognostic benefit seen in RALES (randomised aldactone evaluation study) and EPHESUS (eplerenone postacute myocardial infarction heart failure efficacy and survival study) may also occur in patients with milder CHF already taking standard optimal treatment.
\end{abstract}

R ALES (randomised aldactone evaluation study) showed a $30 \%$ mortality reduction in severe congestive heart failure (CHF) with the addition of spironolactone. ${ }^{1}$ The recent EPHESUS (eplerenone postacute myocardial infarction heart failure efficacy and survival study) confirms this, although as in RALES, the EPHESUS patients had moderate to severe disease. ${ }^{2}$ These two studies now raise the question of whether spironolactone would produce the same benefit in patients with mild or asymptomatic CHF. Indeed the editorial accompanying the EPHESUS paper said that "trials are now needed to determine whether these drugs will be efficacious in less severe patients". A second question is that despite EPHESUS there is still some uncertainty over whether the RALES benefit would occur in CHF in the presence of optimal treatment including concomitant $\beta$ blockade. This uncertainty arises because of the adverse effects of triple neuroendocrine blockade in ValHeFt (valsartan heart failure trial), because the RALES trial predated the use of $\beta$ blockers in CHF, and because the EPHESUS data arise from a different population-that is, patients immediately after a myocardial infarction. To answer both questions posed above, we have now studied the effect of spironolactone in patients with mild (New York Heart Association (NYHF) functional class I-II) CHF taking optimal treatment, including $\beta$ blockers unless contraindicated. A third rationale for our study is to give some practical guidance as to whether doctors would be justified in extrapolating the RALES and EPHESUS results to using spironolactone in patients with mild or asymptomatic CHF.
The main mechanism now thought by most experts to explain why aldosterone blockade reduces mortality in CHF is that aldosterone blockade improves endothelial vascular function. ${ }^{3}$ This has been shown directly only in severe CHF so far, but in agreement is the observation that infused aldosterone causes endothelial dysfunction in normal humans and the observation that aldosterone blockade is antiatherosclerotic in animal studies. ${ }^{4-7}$ Other factors that also contribute to the overall benefit are the beneficial effects of aldosterone blockade on cardiac remodelling, vascular angiotensin converting enzyme (ACE), QT interval, and heart rate variability. ${ }^{4-14}$

To address the question posed in the EPHESUS editorial, we have now conducted a study to determine whether spironolactone improves endothelial function and other prognostic markers in patients with NYHA class I-II CHF taking optimal treatment including $\beta$ blockers (unless contraindicated). The final answer as to whether aldosterone blockade reduces mortality in this setting can be obtained

\footnotetext{
Abbreviations: $A C E$, angiotensin converting enzyme; BNP, $\beta$-type natriuretic peptide; EPHESUS, eplerenone postacute myocardial infarction heart failure efficacy and survival study; FBFR, forearm blood flow ratio; HAD, hospital anxiety and depression; L-NMMA, Nmonomethyl--arginine; MLWHF, Minnesota living with heart failure; NYHA, New York Heart Association; PIIINP, procollagen III N-terminal peptide; QTc, corrected QT interval; QTd, QT dispersion; QTdc, corrected QT dispersion; RALES, randomised aldactone evaluation study; SDNN, standard deviation of all NN intervals; ValHeFt, valsartan heart failure trial
} 
only by an expensive mega-trial. Funding for such a megatrial is only likely to become available if positive results are seen in a study such as this, which measured important surrogates for cardiac death.

\section{METHODS}

\section{Study population}

Fifty seven patients with stable NYHA class I-II CHF were recruited after giving full, informed consent. At diagnosis, their CHF had all been at least class II but optimising their treatment had improved patients substantially into a stable, less symptomatic state. The Tayside committee on medical research ethics approved the study and it complies with the Declaration of Helsinki. Left ventricular systolic dysfunction on echocardiographic, angiographic, or nuclear imaging was mandatory and taken as a left ventricular ejection fraction $<50 \%$ or fractional shortening $<25 \%$ at some time in the recent past. All participants were taking ACE inhibitors or angiotensin II receptor blockers and their individually titrated $\beta$ blocker dose (all for at least six months). All patients had been assessed for $\beta$ blocker treatment so that the subgroup not taking $\beta$ blockers either had a contraindication or were unable to tolerate them. In this way, the whole group was regarded as taking optimal treatment for them. Patients with serum sodium concentration $<130 \mathrm{mmol} / \mathrm{l}$, potassium $>5.0 \mathrm{mmol} / \mathrm{l}$, urea $>10.0 \mathrm{mmol} / \mathrm{l}$, or creatinine $>221 \mu \mathrm{mol} / \mathrm{l}$ were excluded.

\section{Randomisation and drug titration}

Patients were randomly assigned in double blind, crossover fashion to spironolactone (three months) or placebo (three months). After three months, they were crossed over to the opposite treatment for three months. The starting dose of spironolactone was $25 \mathrm{mg} /$ day. After two weeks this was doubled to the same maximum dose $(50 \mathrm{mg})$ as in RALES. If side effects occurred or plasma urea and electrolytes became deranged (criteria above) the dose was halved. Patients unable to tolerate the minimum dose ( $12.5 \mathrm{mg} / 24$ hours) were withdrawn.

\section{Assessments after each treatment period}

The assessments were comprehensive and hence we made them only at the end of each randomised treatment period and not at baseline. This is especially because assessment of endothelial function and vascular ACE require arterial puncture. Therefore, for ethical reasons, we limited assessments to the minimum necessary. Hence, we compared them directly, rather than subtracting baseline values from both, since baselines for each treatment would have then required four rather than two arterial puncture studies. ${ }^{15} 16$

\section{Endothelial function}

Studies were conducted in quiet, temperature controlled (24$26^{\circ} \mathrm{C}$ ) surroundings at $9 \mathrm{am}$. Patients fasted from midnight. Prescribed medication was taken, except diuretics. After 20 minutes' supine rest a 27 gauge steel needle (mounted on a 16 gauge epidural catheter) was positioned in the nondominant brachial artery. After 10 minutes of saline infusion baseline forearm blood flow ratio $(\mathrm{FBFR})^{17}$ was assessed by forearm venous occlusion plethysmography as described in detail elsewhere. ${ }^{4}$ Drugs were serially infused at increasing concentrations and FBFR was assessed during the final two minutes of each concentration. Between each infusate, the infusion set was flushed with saline until FBFR had returned to baseline levels.

\section{Intra-arterial infusions}

The endothelium dependent vasodilator acetylcholine (CIBAVision) was administered at 25, 50, and $100 \mathrm{nmol} / \mathrm{min}$, each for five minutes. Then angiotensin I (Clinalfa) was infused at 64256 and $1024 \mathrm{pmol} / \mathrm{min}$ for seven minutes each. In this model, vasoconstriction elicited by angiotensin I relies entirely on its conversion to angiotensin II. Next angiotensin II (Clinalfa) was infused at 16 and $64 \mathrm{pmol} /$ min for seven minutes each. The competitive nitric oxide synthase inhibitor $\mathrm{N}$-monomethyl-L-arginine (L-NMMA, Clinalfa) was then infused at $4 \mu \mathrm{mol} / \mathrm{min}$ for five minutes. After this, acetylcholine was co-infused with L-NMMA at 50 and $100 \mathrm{nmol} / \mathrm{min}$, each for five minutes. Finally, the endothelium independent vasodilator sodium nitroprusside (David Bull Laboratories) was given at $37.8 \mathrm{nmol} / \mathrm{min}$ for five minutes.

\section{Blood samples}

Samples were collected between 11 am and 1 pm after 30 minutes' supine rest and centrifuged. Plasma was stored at $-70^{\circ} \mathrm{C}$ (peptides) or $-20^{\circ} \mathrm{C}$ (other samples). Blinded operators performed assays in batches. Plasma $\beta$-type natriuretic peptide (BNP) samples were collected into EDTA and aprotonin and measured by radioimmunoassay (Bachem, St Helens, Merseyside, UK). Serum procollagen III N-terminal peptide (PIIINP) concentrations were assessed by an intact radioimmunoassay (Quidel, UK).

\section{QT parameters}

Standard 12 lead ECGs were recorded with a 4700A machine (Hewlett Packard, Palo Alto, California, USA). For each lead, the QT intervals of three consecutive non-ectopic complexes were measured and averaged. A digitising tablet (Calcomp, Anaheim, California, USA) with in-house software was used. The QT interval was measured from QRS onset to T wave cessation. If $U$ waves were present, the end of the QT interval was taken at the nadir between the $\mathrm{T}$ and the $\mathrm{U}$ waves. The corrected QT (QTc) interval was calculated by Bazett's method $(\mathrm{QTC}=\mathrm{QT} / \sqrt{\mathrm{RR}})$. QT dispersion (QTd) was calculated as the difference between the longest and shortest QT intervals. Measurements were performed by one blinded investigator (JEM). Any lead omitted on a patient's first ECG was omitted on the second.

\section{Heart rate variability}

Twenty four hour ambulatory Holter monitoring was undertaken. Patients with pacemakers, atrial fibrillation, or intermittent bundle branch block were excluded. A two channel Tracker II analogue tape recorder (Reynolds Medical, Hertford, Hertfordshire, UK) was used with CMI and CM5 leads. Data were processed with the Pathfinder 600 Analyser (Reynolds Medical) and manually edited ${ }^{18}$ for both time domain (mean RR interval, standard deviation of all NN intervals (SDNN), standard deviation of the averages of NN intervals, SDNN index, root mean square of successive differences between NN intervals, the triangular index) and frequency domain parameters (total power, ultralow frequency, very low frequency, low frequency, and high frequency). ${ }^{19}$

\section{Six minute walk}

Subjects were asked to walk briskly between two markers spaced $20 \mathrm{~m}$ apart.

\section{Questionnaire data}

The Minnesota living with heart failure (MLWHF) and hospital anxiety and depression (HAD) questionnaires were administered..$^{20}$

\section{Statistical analysis}

Forearm blood flow ( $\mathrm{ml} / \mathrm{min} / 100 \mathrm{ml}$ forearm volume) rates were converted to ratios between forearm blood flow in the 
infused arm and that in the control arm. Percentage change in FBFR from the baseline immediately preceding each infusion was calculated. FBFR measurements were analysed by a general linear model with treatment and dose as fixed factors and patient number as a random factor. The interaction between dose and treatment was non-significant in all cases. Other data were compared between treatments by Student's paired $t$ tests. A probability value of $\mathrm{p}<0.05$ was considered significant. Results are expressed as mean (SEM) in the figures.

\section{RESULTS}

Fourteen patients did not complete the study, of whom eight were taking spironolactone (two had cramps and two had hyperkalaemia) and six were given placebo (one experienced lethargy and one died). Six developed intercurrent illness. Two patients withdrew without giving reasons. Forty three patients completed the study (mean (SD) spironolactone dose of 40.1 (2.02) $\mathrm{mg}$ ).

\section{Clinical characteristics}

Weight and NYHA class were unchanged (table 1). Systolic and diastolic blood pressures were significantly lower among patients taking spironolactone $(p=0.004$ and $p=0.005$, respectively).

\section{Endothelial function}

Endothelial function and vascular ACE was measured in only 40 patients, since those taking warfarin $(n=3)$ obviously cannot undergo arterial puncture studies. Blood pressure was unchanged during studies (table 4). Spironolactone significantly improved acetylcholine induced endothelium dependent vasodilatation $(\mathrm{p}=0.045)$ (fig 1$)$, blunted angiotensin I induced vasoconstriction ( $p=0.006)$ (fig 2$)$, and augmented angiotensin II induced vasoconstriction $(\mathrm{p}=0.044)$ (fig 3). Responses to sodium nitroprusside, L-NMMA, and co-infusion of L-NMMA and acetylcholine were unaltered (fig 4). Mean (SD) sodium nitroprusside responses were 340 (156)\% with placebo and 369 (189)\% with spironolactone $(\mathrm{p}=0.399, t$ test $)$.

\section{Table 1 Baseline clinical data}

\begin{tabular}{ll}
\hline & Mean (SD) \\
\hline Age (years) & $67.5(7.05)$ \\
Male/female & $35 / 8$ \\
NYHA class I/II & $15 / 28$ \\
HF aetiology HT/IHD/DCM & $9 / 29 / 5$ \\
IHD & $38(88 \%)$ \\
LVH & $9(21 \%)$ \\
NIDDM & $4(9 \%)$ \\
AF & $1(2 \%)$ \\
SBP (mm Hg) & $137(21.0)$ \\
DBP (mm Hg) & $76.8(9.79)$ \\
Sodium (mmol/I) & $139(2.78)$ \\
Potassium (mmol/I) & $4.37(0.34)$ \\
Urea (mmol/I) & $7.29(2.50)$ \\
Creatinine ( $\mu m o l / I)$ & $111(27.2)$ \\
Furosemide (mg) & $33.0(38.0)$ \\
Aspirin & $38(88 \%)$ \\
Warfarin & $3(12 \%)$ \\
ACE inhibitor/ARB & $36(84 \%) / 7(16 \%)$ \\
Statin & $25(58 \%)$ \\
$\beta$ Blocker & $31(72 \%)$ \\
Digoxin & $4(9 \%)$ \\
\hline
\end{tabular}

$A C E I$, angiotensin converting enzyme inhibitor; $A F$, atrial fibrillation; $A R B$, angiotensin receptor blocker; DBP, diastolic blood pressure; DCM, dilated cardiomyopathy; HF, heart failure; IHD, ischaemic heart disease; LVH, left ventricular hypertrophy; NIDDM, non-insulin dependent diabetes mellitus; NYHA, New York Heart Association; SBP, systolic blood pressure.

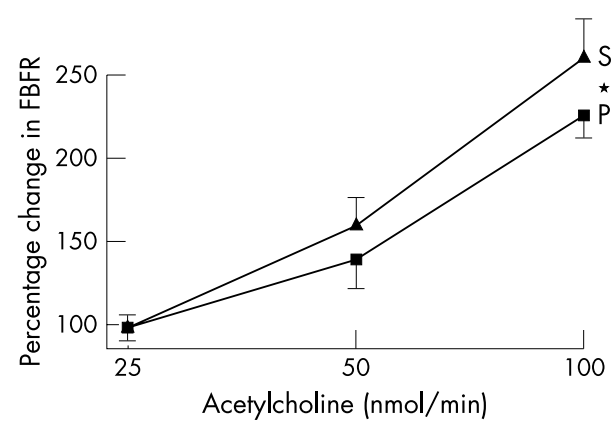

Figure 1 Forearm blood flow ratio (FBFR) response to acetylcholine after spironolactone (S) or placebo (P). ${ }^{*} \mathrm{p}<0.05$.

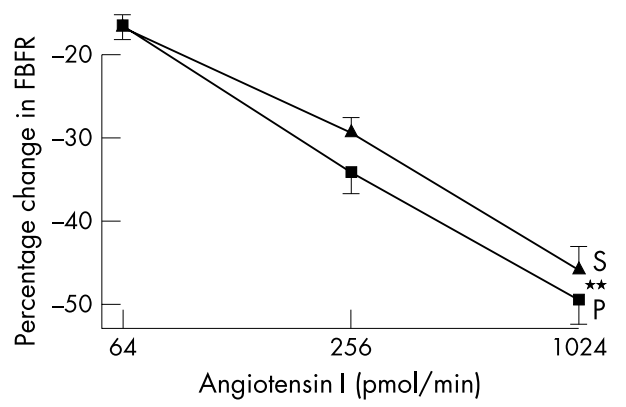

Figure 2 Forearm blood flow ratio (FBFR) response to angiotensin I after spironolactone (S) or placebo (P). ${ }^{* *} \mathrm{p}<0.01$.

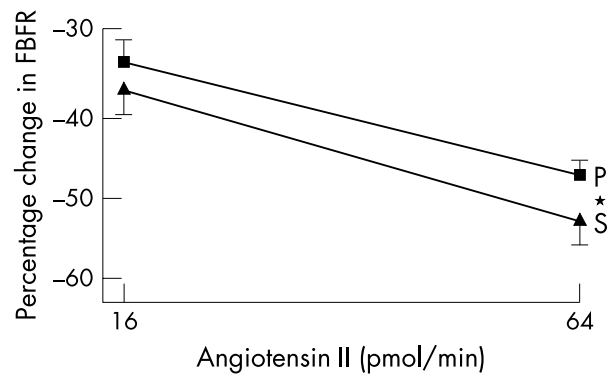

Figure 3 Forearm blood flow ratio (FBFR) response to angiotensin II after spironolactone $(\mathrm{S})$ or placebo $(\mathrm{P}) .{ }^{*} \mathrm{p}<0.05$.

\section{Blood analysis results}

The most relevant differences between placebo and spironolactone administration were that both plasma BNP $(\mathrm{p}=0.039)$ and plasma PIIINP fell $(\mathrm{p}=0.000)$ with spironolactone. The PIIINP fall was greater when placebo PIIINP was $>3 \mu \mathrm{g} / \mathrm{l}$ as in RALES.

\section{QT parameters}

QT indices were significantly reduced with spironolactone: QT $(p=0.009)$, QTc $(p=0.002)$, QTd $(p=0.037)$, and QTdc $(\mathrm{p}=0.032)($ table 2$)$.

\section{Heart rate variability data}

Spironolactone significantly reduced ventricular extrasystoles $(\mathrm{p}=0.030) \quad($ table 3$)$. Couplets and triplets fell nonsignificantly. Heart rate variability measures did not improve, including early morning heart rate variability. The use of $\beta$ blockers in this study appears to have negated the effect of spironolactone on heart rate variability seen in previous studies. ${ }^{14}$ 


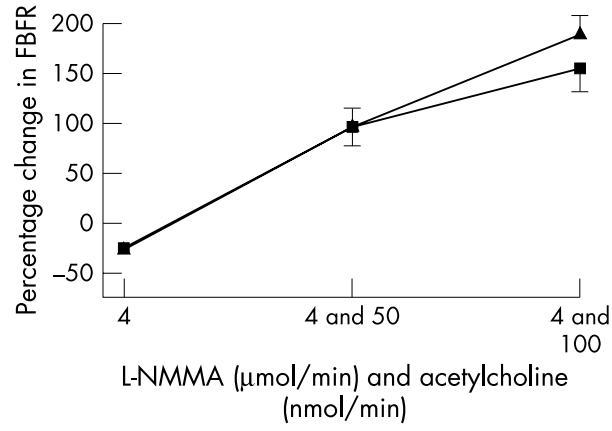

Figure 4 Forearm blood flow ratio (FBFR) response to $\mathrm{N}$-monomethyl-Larginine (L-NMMA) alone and co-infused with acetylcholine after spironolactone (S) or placebo (P).

Six minute walk distance

Six minute walk distance was unaltered (table 2).

\section{Questionnaire data}

Total MLWHF questionnaire scores worsened significantly with spironolactone $(\mathrm{p}=0.044)$ but there was no increase in physical dimension score (table 2). Total HAD and anxiety scores were also significantly worse after spironolactone $(p=0.035$ and $p=0.021$, respectively). These results were surprising but perhaps spironolactone produces subtle adverse effects that adversely influence quality of life. One possibility is the well known sexual side effects of spironolactone such as impotence and gynaecomastia.

\section{Influence of $\beta$ blockade}

The improvements in PIIINP, BNP, endothelial function (acetylcholine), vascular ACE (angiotensin I vasoconstriction), and QTc were also seen when the analysis was limited to the smaller number of patients who were taking $\beta$ blockers $(\mathrm{p}=0.000, \mathrm{p}=0.016, \mathrm{p}=0.076, \mathrm{p}=0.025$, and $\mathrm{p}=$ 0.002 , respectively). This shows that spironolactone still has beneficial effects even when prescribed as a third neuroendocrine blocking agent.

\section{DISCUSSION}

Our main finding is that spironolactone improved our primary end point of endothelial function in patients with class I-II CHF taking optimal treatment. There are now seven separate studies showing that endothelial dysfunction is associated with future cardiovascular events. ${ }^{22-28}$ In addition, the two treatments that are known to improve prognosis in CHF also improve endothelial function-that is, ACE inhibitors and spironolactone. ${ }^{429}$ Thus, spontaneous abnormalities in endothelial function in general and treatment induced changes in endothelial function in CHF have so far always predicted prognosis. Indeed, a recent editorial in Circulation called endothelial function a "barometer of vascular health representing an orchestrated response to the many processes which contribute to atherosclerosis development and progression". ${ }^{30}$

Angiotensin I induced vasoconstriction was blunted by spironolactone, implying reduced angiotensin I to angiotensin II conversion over and above that achieved with chronic ACE inhibitor treatment, as previously shown in patients with more severe $\mathrm{CHF} .{ }^{4}$ This also agrees with data showing that aldosterone increases ACE mRNA 23-fold in tissue culture $^{31}$ and with other experimental data. ${ }^{32}{ }^{33}$ In our study this was despite spironolactone significantly increasing angiotensin II induced vasoconstriction, which would have tended to mask the ability of our study to detect a spironolactone induced reduction in angiotensin I induced
Table 2 Differences in experimental data between treatment with spironolactone and placebo

\begin{tabular}{|c|c|c|c|}
\hline & Placebo & Spironolactone & $\mathrm{p}$ Value \\
\hline Weight (kg) & $77.2(10.2)$ & $76.8(9.70)$ & 0.108 \\
\hline $\mathrm{SBP}(\mathrm{mm} \mathrm{Hg})$ & $135(21.8)$ & $126(24.5)$ & $0.004^{* *}$ \\
\hline $\mathrm{DBP}(\mathrm{mm} \mathrm{Hg})$ & $77.4(9.90)$ & $72.3(11.8)$ & $0.005^{* *}$ \\
\hline HR (beats/min) & $60.0(12.2)$ & $58.8(7.34)$ & 0.475 \\
\hline Sodium (mmol/l) & $137(4.20)$ & $135(4.30)$ & $0^{* *}$ \\
\hline Potassium (mmol/l) & $4.36(0.41)$ & $4.72(0.41)$ & 0 ** \\
\hline Urea (mmol/l) & $6.15(1.97)$ & $7.93(7.93)$ & $0^{* *}$ \\
\hline Creatinine $(\mu \mathrm{mol} / \mathrm{l})$ & $91.0(27.0)$ & $101(33.0)$ & $0^{* *}$ \\
\hline Magnesium (mmol/l) & $0.89(0.07)$ & $0.87(0.07)$ & $0.044^{*}$ \\
\hline Urate (mmol/l) & $0.37(0.08)$ & $0.37(0.08)$ & 0.695 \\
\hline $\mathrm{BNP}(\mathrm{pg} / \mathrm{ml})$ & $48.5(29.7)$ & $36.8(28.5)$ & $0.039 *$ \\
\hline PIIINP( $\mu \mathrm{g} / \mathrm{I})$ & $3.767(1.157)$ & $3.156(1.123)$ & $0^{* *}$ \\
\hline Noradrenaline (pg/ml) & $769(361)$ & $851(383)$ & 0.114 \\
\hline Adrenaline $(\mathrm{pg} / \mathrm{ml})$ & $82.8(88.9)$ & $94.7(74.4)$ & 0.416 \\
\hline MLWHF score & $16.2(15.9)$ & $18.8(18.6)$ & $0.044^{*}$ \\
\hline Physical score & $8.31(7.97)$ & $8.86(8.73)$ & 0.47 \\
\hline Emotional score & $3.31(4.55)$ & $4.02(5.41)$ & 0.227 \\
\hline HAD score & $7.05(6.43)$ & $8.24(6.90)$ & $0.035^{*}$ \\
\hline Anxiety score & $3.76(3.71)$ & $4.24(3.75)$ & 0.21 \\
\hline Depression score & $3.31(3.29)$ & $4.00(3.84)$ & $0.023^{*}$ \\
\hline 6 minute distance $(\mathrm{m})$ & $472(81.1)$ & $466(13.9)$ & 0.438 \\
\hline $\mathrm{PWV}(\mathrm{m} / \mathrm{s})$ & $8.36(1.27)$ & $8.23(1.23)$ & 0.447 \\
\hline Augmentation & 15.7 (8.91) & $14.3(7.04)$ & 0.219 \\
\hline Buckberg & $166(31.0)$ & 170 (32.7) & 0.389 \\
\hline QT (ms) & $465(54.7)$ & $447(56.5)$ & $0.009^{* *}$ \\
\hline QTc (ms) & $473(43.1)$ & $455(35.4)$ & $0.002^{* *}$ \\
\hline QTd (ms) & $84.5(41.3)$ & $72.1(32.3)$ & $0.037^{*}$ \\
\hline QTdc (ms) & $86.0(39.9)$ & $73.4(30.6)$ & $0.032^{*}$ \\
\hline $\mathrm{BSA}\left(\mathrm{m}^{2}\right)$ & $1.93(0.16)$ & $1.92(0.16)$ & 0.393 \\
\hline LVIDd $(\mathrm{cm})$ & $5.40(0.86)$ & $5.06(0.94)$ & $0.006^{* *}$ \\
\hline IVSd $(\mathrm{cm})$ & $1.15(0.30)$ & $1.12(0.29)$ & 0.587 \\
\hline LVPWd $(\mathrm{cm})$ & $1.04(0.26)$ & $1.11(0.25)$ & 0.25 \\
\hline $\operatorname{LVM}(g)$ & $235(81.2)$ & $215(71.6)$ & $0.022^{*}$ \\
\hline LVMI $\left(\mathrm{g} / \mathrm{m}^{2}\right)$ & $122(41.0)$ & $112(36.3)$ & $0.036^{*}$ \\
\hline
\end{tabular}

Data are mean (SD). ${ }^{*} \mathrm{p}<0.05 ;{ }^{* *} \mathrm{p}<0.01$.

$B N P$, $\beta$-type natriuretic peptide; BSA, body surface area; HAD, hospital anxiety and depression; HR, heart rate; IVSd, interventricular septum thickness; LVIDd, left ventricular end diastolic diameter; LVM, left ventricular mass; LVMI, left ventricular mass index; LVPWd, left ventricular posterior wall thickness; MLWHF, Minnesota living with heart failure; PIIINP, procollagen III N-terminal peptide; PWV, pulse wave velocity; QT, corrected QT interval; QTd, QT dispersion; QTdc, corrected QT dispersion.

vasoconstriction. We hypothesise that adding spironolactone produces additional blockade of angiotensin I to angiotensin II conversion, which results in reduced local angiotensin II. Such an effect has been seen before in patients with severe CHF. ${ }^{4}$ We speculate that this may then upregulate the vascular angiotensin II type I receptors, which manifests itself here as an amplified vasoconstrictive response to exogenous angiotensin II. Such upregulation of a receptor when its natural ligand is reduced is an accepted cornerstone of pharmacological theory even if it has not been studied before in this precise scenario. For that reason, our speculation here is the most likely explanation for our results. For clarity, we have used the term "vascular ACE" in earlier sections of this paper but, strictly speaking, we can only really say that spironolactone altered vascular angiotensin I to angiotensin II conversion, as we cannot know whether in our study spironolactone altered ACE, non-ACE pathways, or both. $^{34}$

In this study, we used BNP as an index of intracardiac pressure/volume and left ventricular remodelling. We also used PIIINP as an index of ventricular collagen turnover. Use of these plasma markers in this way is well established. Furthermore, both such markers are prognostic markers in CHF. ${ }^{12} 35{ }^{36}$ Consistent reductions in both suggest improved left ventricular remodelling. Our intention was to confirm this with echocardiography but good images were obtained for only 21 patients because smoking and obesity were 
Table 3 Differences in heart rate variability parameters between treatment with spironolactone and placebo

\begin{tabular}{|c|c|c|c|}
\hline & Placebo & Spironolactone & p Value \\
\hline Normal QRS & 92991 (12933) & 93440 (14 048) & 0.648 \\
\hline SVT & $0.38(0.85)$ & $0.51(1.52)$ & 0.57 \\
\hline Aberrants & 1548 (3571) & 1054 (2845) & 0.211 \\
\hline Extrasystoles & 400 (832) & $300(711)$ & $0.03^{*}$ \\
\hline Couplets & $98.3(370)$ & $22.4(57)$ & 0.167 \\
\hline Triplets & 12.7 (74.7) & $0.62(1.76)$ & 0.317 \\
\hline Salvos & 2.15 (11.7) & $0.18(0.45)$ & 0.291 \\
\hline VT & $0.08(0.27)$ & $0.10(0.31)$ & 0.661 \\
\hline Bradycardia & $53.6(151)$ & 47.7 (139) & 0.835 \\
\hline Dropped beat & 3.03 (14.9) & $0.69(2.66)$ & 0.251 \\
\hline Pauses & $0.00(0.00)$ & $0.00(0.00)$ & 0.294 \\
\hline \multicolumn{4}{|l|}{ Maximum HR } \\
\hline (beats/min) & $100(15.8)$ & $98.5(15.1)$ & 0.241 \\
\hline $\begin{array}{l}\text { Minimum HR } \\
\text { (beats/min) }\end{array}$ & $50.6(6.29)$ & $51.3(6.73)$ & 0.806 \\
\hline Total QRS & 94803 (12 564) & 94538 (13 706) & $0.027^{\star}$ \\
\hline Triangle index & $33.7(9.61)$ & $33.0(9.66)$ & 0.544 \\
\hline Mean RR (ms) & 932 (131) & 919 (127) & 0.293 \\
\hline SDNN (ms) & $114(28.7)$ & $113(22.7)$ & 0.803 \\
\hline SDNNI (ms) & $47.9(13.1)$ & $44.6(12.4)$ & 0.041 \\
\hline SDANN (ms) & $99.2(26.6)$ & $100(21.2)$ & 0.862 \\
\hline RMSSD (ms) & $28.1(9.78)$ & $25.8(9.52)$ & 0.039 \\
\hline$\%$ analysed & $94.6(5.57)$ & $95.7(4.60)$ & 0.161 \\
\hline $\operatorname{VLF}\left(\mathrm{ms}^{2}\right)$ & 700 (439) & 697 (387) & 0.974 \\
\hline $\operatorname{LF}\left(\mathrm{ms}^{2}\right)$ & 190 (117) & $166(98.5)$ & 0.145 \\
\hline $\mathrm{HF}\left(\mathrm{ms}^{2}\right)$ & $107(54.6)$ & $93.1(60.9)$ & 0.13 \\
\hline Total power $\left(\mathrm{ms}^{2}\right)$ & $1006(568)$ & 973 (515) & 0.719 \\
\hline Normalised LF & $57.3(13.8)$ & $57.5(9.10)$ & 0.97 \\
\hline Normalised HF & $40.2(10.8)$ & $38.4(9.89)$ & 0.33 \\
\hline LF/HF ratio & $2.05(0.99)$ & $2.24(1.05)$ & 0.235 \\
\hline
\end{tabular}

Data are mean (SD). ${ }^{*} \mathrm{p}<0.05$.

$\mathrm{HF}$, high frequency; LF, low frequency; RMSSD, root mean square of successive differences between NN intervals; SDANN, standard deviation of the averages of NN intervals; RMSSD, root mean square of successive differences between NN intervals; SDNN, standard deviation of all NN intervals; SDNNI, SDNN index; SVT, supraventricular tachycardia; VLF, very low frequency; VT, ventricular tachycardia.

common in our cohort. Even in these 21 patients, we did find significant confirmatory reductions in left ventricular internal diameter $(5.40(0.18) \mathrm{cm}$ to $5.06(0.19) \mathrm{cm}, \mathrm{p}=0.006)$ and left ventricular mass index (122 (8) g/m² to $112(7) \mathrm{g} / \mathrm{m}^{2}$, $\mathrm{p}=0.036)$, but these echocardiographic results are a bit unreliable because they refer to only a subset of patients. Nevertheless, changes in BNP and PIIINP are so well linked to prognosis and remodelling in CHF that favourable changes in both of them are a further promising sign. ${ }^{12}{ }^{35}$

It is possible that the blood pressure reduction caused the improvements in endothelial function and left ventricular remodelling. However, this appears unlikely, as blood pressure did not change in our previous study in severe CHF where the improvement in endothelial function was of a greater magnitude than here. ${ }^{4}$ As to left ventricular remodelling, spironolactone's effects on remodelling have twice before been shown without a blood pressure change. ${ }^{11}{ }^{13}$ However, we cannot exclude blood pressure changes contributing to the effects seen in this study.

Increased QT intervals are associated with increased mortality. ${ }^{37}$ Spironolactone is known to reduce QT and QTd in class III-IV CHF. ${ }^{14}$ In keeping with this, we observed significant shortening of QT, QTc, QTd, and QTdc in these patients with milder CHF. These improvements may be associated with the reduced arrhythmogenicity that we saw here, although counting ventricular extrasystoles is not a particularly good measure of arrhythmogenicity.

It is interesting that these benefits occurred here without alteration in body weight. Sceptics have previously suggested that the RALES result was due to improved diuresis with spironolactone. The lack of accurate weight data in all previous studies has fuelled this possibility. We have now
Table 4 Basal flow rates during plethysmographic study

\begin{tabular}{ll}
\hline & Mean (SD) \\
\hline Placebo control arm & $2.66(1.06)$ \\
Placebo infusion arm & $2.67(0.99)$ \\
Spironolactone control arm & $2.71(0.86)$ \\
Spironolactone infusion arm & $2.74(0.75)$ \\
\hline There were no significant differences between the spironolactone and \\
placebo basal flow rates ( $p=0.78$ for control arm and $p=0.65$ for \\
infusion arm).
\end{tabular}

provided accurate weight data and shown that increased diuresis per se is unlikely to contribute.

The fact that we measured so many things could be seen as a weakness, as some positive effects may then be seen by chance. This is unlikely, since all of the positive effects we found have been seen before in patients with more severe CHF, which makes it unlikely that these effects occurred purely by chance in these mild to asymptomatic patients.

Spironolactone did appear to worsen significantly one quality of life score and depression scores. Unlike the positive effects, such effects have not been seen before. These adverse scores may relate to adverse side effects of the drug, which were too subtle to lead to their being recognised as adverse drug effects as such. In addition, these patients had such mild CHF that it may have been difficult to improve their quality of life when it was fairly normal to start with. Obviously this is an important issue needing further study, since this finding may detract importantly from the beneficial effects seen in vascular and other prognostic markers.

\section{Conclusion}

Spironolactone improves endothelial nitric oxide bioactivity, vascular ACE activity, QT interval length, and other prognostic markers (BNP, PIIINP) when added to optimally treated patients with class I-II CHF. Although such effects have been seen before in moderate to severe CHF, the key point here is that we found them the first time ever in patients with mild CHF already taking optimal treatment. Most pertinent is that this is the first study to show beneficial effects in mild to asymptomatic CHF on the main mechanism that is thought to underlie its benefits-that is, endothelial function. $^{3-7}$ A mega-trial should now be undertaken to establish whether these improvements in surrogate markers translate into a significant prognostic benefit and in particular to see whether any putative benefit outweighs the not inconsiderable and unpredictable risks of hyperkalaemia when spironolactone and ACE inhibitors are given together in certain patients with $\mathrm{CHF}^{38}{ }^{39}$ Such mega-trials are so expensive that underpinning data such as these are essential before any funding body is going to be persuaded to release the necessary funds.

\section{ACKNOWLEDGEMENTS}

We thank the Northwood Trust, Dundee, for funding the study and Lesley McFarlane and Valerie Godfrey for their expert technical assistance.

\section{Authors' affiliations}

J E Macdonald, A D Struthers, Department of Clinical Pharmacology and Therapeutics, Ninewells Hospital and Medical School, Dundee, UK N Kennedy, Department of Medical Physics, Ninewells Hospital and Medical School

\section{REFERENCES}

1 Pitt B, Zannad F, Remme WJ, et al. The effect of spironolactone on morbidity and mortality in patients with severe heart failure. Randomized aldactone evaluation study investigators. N Engl J Med 1999;341:709-17. 
2 Pitt B, Remme WJ, Zannad F, et al. Eplerenone, a selective aldosterone blocker, in patients with LV dysfunction after MI. N Engl J Med 2003;384:1309-21.

3 Struthers AD. Effect of aldosterone on the vascular bed: introducing aldosterone induced vasculopathy. In Braunwald E, ed. Harrison's advances in cardiology. New York: McGraw Hill, 2003:12-7.

4 Farquharson CA, Struthers AD. Spironolactone increases nitric oxide bioactivity, improves endothelial vasodilator dysfunction, and suppresses vascular angiotensin I/angiotensin II conversion in patients with chronic heart failure. Circulation 2000;101:594-7.

5 Farquharson C, Struthers AD. Aldosterone induces acute endothelial dysfunction in vivo in man: evidence for an aldosterone induced vasculopathy. Clin Sci 2002;103:425-31.

6 Rajagopalan S, Duquaine D, King S, et al. Mineralocorticoid receptor antagonism in experimental atherosclerosis. Circulation 2002:105:2212-6.

7 Rocha R, Chander PHN, Khanna K, et al. Mineralocorticoid blockade reduces vascular injury in stroke prone hypertensive rats. Hypertension 1998; $31: 451-8$

8 Barr CS, Lang CC, Hanson J, et al. Effects of adding spironolactone to an angiotensin-converting enzyme inhibitor in chronic congestive heart failure secondary to coronary artery disease. Am J Cardiol 1995;76:1259-65.

9 Kinugawa T, Ogino K, Kato $M$, et al. Effects of spironolactone on exercise capacity and neurohormonal factors in patients with heart failure treated with loop diuretics and angiotensin-converting enzyme inhibitor. Gen Pharmacol 1998;31:93-9.

10 MacFadyen RJ, Barr CS, Struthers AD. Aldosterone blockade reduces vascular collagen turnover, improves heart rate variability and reduces early morning rise in heart rate in heart failure patients. Cardiovasc Res 1997:35:30-4

11 Tsutamoto T, Wada A, Maeda K, et al. Effect of spironolactone on plasma brain natriuretic peptide and left ventricular remodeling in patients with congestive heart failure. J Am Coll Cardiol 2001;37:1228-33.

12 Zannad F, Alla F, Dousset B, on behalf of RALES Investigators, et al Limitation of excessive extracellular matrix turnover may contribute to survival benefit of spironolactone therapy in patients with congestive heart failure: insights from the randomized aldactone evaluation study (RALES). Circulation 2000;102:2700-6.

13 Cicoira M, Zanolla L, Rossi A, et al. Long-term, dose-dependent effects of spironolactone on left ventricular function and exercise tolerance in patients with chronic heart failure. J Am Coll Cardiol 2002;40:304-10

14 Yee KM, Pringle SD, Struthers AD. Circadian variation in the effects of aldosterone blockade on heart rate variability and QT dispersion in congestive heart failure. J Am Coll Cardiol 2001;37:1800-7.

15 Farquharson C, Butler R, Hill A, et al. Allopurinol improves endothelial dysfunction in chronic heart failure. Circulation 2002;106:221-6.

16 Landmesser U, Drexler H. Allopurinol and endothelial function in heart failure. Circulation 2002;106:173-5.

17 Benjamin N, Calver A, Collier J, et al. Measuring forearm blood flow and interpreting the responses to drugs and mediators. Hypertension 1995;25:918-23

18 Molgaard H. Evaluation of the Reynolds Pathfinder II system for $24 \mathrm{~h}$ heart rate variability analysis. Eur Heart J 1991;12:1153-62.

19 Anon. Heart rate variability: standards of measurement, physiological interpretation and clinical use. Task Force of the European Society of Cardiology and the North American Society of Pacing and Electrophysiology. Circulation 1996;93:1043-65.
20 Rector TS, Kubo SH, Cohn JN. Validity of the Minnesota living with heart failure questionnaire as a measure of therapeutic response to enalapril or placebo. Am J Cardiol 1993;71:1106-7.

21 Zigmond AS, Snaith RP. The hospital anxiety and depression scale. Acto Psychiatr Scand 1983:67:361-70.

22 Gokce N, Keaney JF Jr, Hunter LM, et al. Risk stratification for postoperative cardiovascular events via noninvasive assessment of endothelial function: a prospective study. Circulation 2002;105:1567-72.

23 Heitzer T, Schlinzig T, Krohn K, et al. Endothelial dysfunction, oxidative stress, and risk of cardiovascular events in patients with coronary artery disease. Circulation 2001;104:2673-8

24 Neunteufl T, Heher S, Katzenschlager R, et al. Late prognostic value of flowmediated dilation in the brachial artery of patients with chest pain. Am J Cardiol 2000;86:207-10.

25 Perticone F, Ceravolo R, Pujia A, et al. Prognostic significance of endothelial dysfunction in hypertensive patients. Circulation 2001;104:191-6.

26 Schachinger V, Britten MB, Zeiher AM. Prognostic impact of coronary vasodilator dysfunction on adverse long-term outcome of coronary heart disease. Circulation 2000;10:1899-906.

27 Al Suwaidi J, Hamasaki S, Higano ST, et al. Long-term follow-up of patients with mild coronary artery disease and endothelial dysfunction. Circulation 2000;101:948-54

28 Halcox JPJ, Schenke WH, Zalos G, et al. Prognostic value of coronary vascular endothelial dysfunction. Circulation 2002;106:653-8

29 Nakamura M, Funakoshi T, Arakawa N, et al. Effect of ACE inhibitors on endothelium dependent peripheral vasodilatation in patients with chronic heart failure. J Am Coll Cardiol 1994;24:1321-7.

30 Vita JA, Keaney JF. Endothelial function: a barometer of cardiovascular risk. Circulation 2002;106:640-2.

31 Harada E, Yoshimura $M$, Yasue $\mathrm{H}$, et al. Aldosterone induces angiotensinconverting-enzyme gene expression in cultured neonatal rat cardiocytes. Circulation 2001; 104:137-9.

32 Sun Y, Ratajska A, Zhou G, et al. ACE and myocardial fibrosis in the rat receiving All or aldosterone. J Lab Clin Med 1993;122:395-403.

33 Robert V, Heymes $\mathrm{C}$, Silvestre JS, et al. $\mathrm{AT}_{1}$ receptor sub-type as a cardiac target of aldosterone: role in aldosterone salt induced fibrosis. Hypertension 1999;33:981-6.

34 Farquharson CA, Struthers AD. Gradual reactivation over time of vascular tissue angiotensin I to angiotensin II conversion during chronic lisinopril therapy in chronic heart failure. J Am Coll Cardiol 2002;39:767-75

35 Troughton RW, Frampton CM, Yandle TG, et al. Treatment of heart failure guided by plasma N-BNP levels improves outcome. Lancet 2000;355:1126-30.

36 Tsutamoto T, Wada A, Maeda K, et al. Plasma brain natriuretic peptide level as a biochemical marker of morbidity and mortality in patients with asymptomatic or minimally symptomatic left ventricular dysfunction: comparison with plasma angiotensin II and endothelin-1. Eur Heart $J$ 1999;20:1799-807.

37 Wong KYK, MacWalter RS, Douglas D, et al. Long QTc predicts future cardiac death in stroke survivors. Heart 2003;89:377-89.

38 Schepkens $H$, Vanholder R, Billiouwv JM, et al. Life threatening hyperkalaemia during combined therapy with ACE inhibitors and spironolactone: an analysis of 25 cases. Am J Med 2001; 110:438-41

39 Berry C, McMurray JJV. Serious adverse events experienced by patients with chronic heart failure taking spironolactone. Heart 2001;85:e8 